\title{
Commercially Available Gene Expression Assays as Predictive Tools for Adjuvant Radiotherapy? A Critical Review
}

\author{
David Krug $^{a}$ René Baumann ${ }^{\text {a, b }}$ Wilfried Budach ${ }^{c}$ Marciana Nona Dumad \\ Jürgen Dunst ${ }^{\mathrm{a}}$ Petra Feyer ${ }^{\mathrm{e}}$ Rainer Fietkau ${ }^{f}$ Wulf Haase $^{g}$ Wolfgang Harms ${ }^{\mathrm{h}}$ \\ Thomas Hehr ${ }^{i}$ Marc D. Piroth ${ }^{j}$ Felix Sedlmayerk Rainer Souchon' \\ Frederik Wenz $^{\mathrm{m}}$ Rolf Sauer ${ }^{\mathrm{f}} \quad$ Breast Cancer Expert Panel of the German Society \\ of Radiation Oncology (DEGRO)

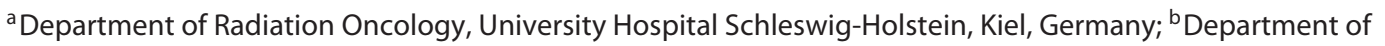 \\ Radiation Oncology, St. Marien-Krankenhaus, Siegen, Germany; ${ }^{\mathrm{C} D e p a r t m e n t ~ o f ~ R a d i a t i o n ~ O n c o l o g y, ~ U n i v e r s i t y ~}$ \\ Hospital Düsseldorf, Düsseldorf, Germany; ${ }^{\mathrm{d}}$ Department of Radiation Oncology, University Hospital Jena, Jena,

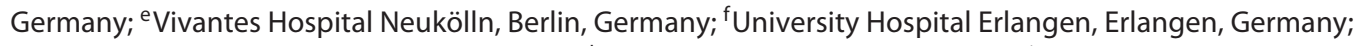

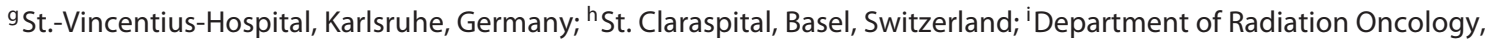 \\ Marienhospital Stuttgart, Stuttgart, Germany; ${ }^{j}$ HELIOS University Hospital Wuppertal, Witten/Herdecke University,

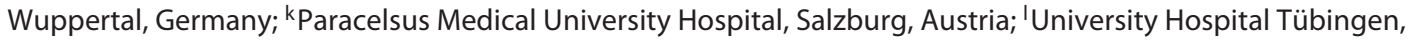

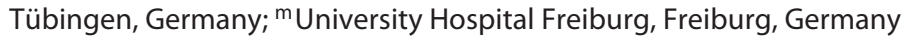

\section{Keywords}

Breast cancer · Radiotherapy · Oncotype DX · Predictive marker $\cdot$ Gene expression assay

\footnotetext{
Abstract

Background: Gene expression assays are increasingly used for decision-making regarding adjuvant chemotherapy in patients with hormone receptor-positive, HER2-negative breast cancer. There are some clinical situations in which there is also a need for better prognostic and predictive markers to better estimate the amount of benefit from adjuvant radiotherapy. The rising availability of gene expression analyses prompts the question whether their results can also be used to guide clinical decisions regarding adjuvant radiation. Summary: Multiple studies suggest a correlation between results from gene expression assays and locoregional recurrence rates. Only few publications addressed the predictive value of results from gene expression analysis for the
}

role of adjuvant radiotherapy in different settings. Key Messages: To date, the available evidence on the possible predictive value of gene expression assays for radiotherapy does not support their inclusion into the decision-making process for adjuvant radiation. This is due to methodological weaknesses and limitations regarding patient selection, the nonrandomized design of all studies in terms of radiotherapy use, and limited availability of tissue from prospective trials. Thus, utilization of the present knowledge for clinical indication of radiotherapy should be very cautious.

C 2020 S. Karger AG, Basel

\section{Introduction}

Since the establishment of breast cancer molecular subtyping in the early 2000s $[1,2]$, the interest in molecular characterization of breast cancer for prognostic and therapeutic purposes has grown exponentially. Although 
Table 1. Commercially available gene expression assays for breast cancer patients

\begin{tabular}{lllll}
\hline & Oncotype DX & Prosigna/PAM50 & EndoPredict & MammaPrint \\
\hline Tissue for analysis & FFPE & FFPE & FFPE & Fresh frozen \\
\hline Technique & qRT-PCR & qRT-PCR & qRT-PCR & RNA microarray \\
\hline Number of genes & 21 & 50 & 11 & 70 \\
\hline Incorporation of clinical parameters Yes (recurrence score) & Yes (risk of recurrence) & Yes (EPclin) & No \\
\hline Central testing & Yes & No & No & Yes \\
\hline Target population & ER positive, endocrine & Postmenopausal, ER \\
& therapy & positive, HER2 negative, & positive, HER2 negative, \\
endocrine therapy & $<70$ years \\
\hline Prospective validation & TAILORx & - & - & MINDACT \\
\hline Risk group stratification & PLAN-B & & & 2 tiered \\
\hline
\end{tabular}

FFPE, formalin-fixed paraffin-embedded; qRT-PCR, quantitative reverse transcriptase polymerase chain reaction.

Table 2. Clinical scenarios regarding adjuvant radiotherapy for breast cancer with potential usefulness of additional prognostic/predictive information

\begin{tabular}{|c|c|c|c|}
\hline Clinical scenario & Patient characteristics & Research question & Clinical endpoints of interest \\
\hline \multirow[t]{2}{*}{$\begin{array}{l}\text { Low-risk early-stage } \\
\text { breast cancer }\end{array}$} & \multirow{2}{*}{$\begin{array}{l}\text { pT1 } 1 \text { N0, ER positive, } \\
\text { HER } 2 \text { negative, G1-2, } \\
\text { age }>65 \text { years }\end{array}$} & $\begin{array}{l}\text { Omission of adjuvant whole-breast } \\
\text { irradiation after breast-conserving surgery }\end{array}$ & \multirow[t]{2}{*}{$\begin{array}{l}\text { - Local recurrence rate } \\
\text { - Risk of secondary mastectomy }\end{array}$} \\
\hline & & Accelerated partial breast irradiation & \\
\hline \multirow[t]{2}{*}{$\begin{array}{l}\text { Intermediate-risk } \\
\text { early-stage breast } \\
\text { cancer }\end{array}$} & pT1-2 pN0-1 & $\begin{array}{l}\text { Addition of regional nodal irradiation to } \\
\text { whole-breast irradiation }\end{array}$ & $\begin{array}{l}\text { - Locoregional recurrence rate } \\
\text { - Distant recurrence rate } \\
\text { - Disease-free survival } \\
\text { - Overall survival }\end{array}$ \\
\hline & $\begin{array}{l}\text { pT1-2 pN1 } \\
\text { pT3 N0 }\end{array}$ & Post-mastectomy radiotherapy & $\begin{array}{l}\text { - Locoregional recurrence rate } \\
\text { - Disease-free survival } \\
\text { - Overall survival }\end{array}$ \\
\hline
\end{tabular}

current clinical guidelines for breast cancer still base the therapeutic decision-making on clinical (age) and pathological parameters (tumor and nodal stage) and results from analytical methods, such as immunohistochemistry (estrogen receptor [ER], progesterone receptor [PR], human epidermal growth factor 2 [HER2], Ki67) and in situ hybridization (for HER2), some have also implemented the results of gene expression analysis-based assays. Currently, several gene expression assays have been approved for clinical use (for an overview, see Table 1), all of which have been developed to estimate the risk of distant metastases and, hence, to guide the decision on whether to use adjuvant chemotherapy in hormone receptor-positive breast cancer. All of these assays have been clinically validated for their prognostic discrimination among subgroups of patients based on retrospective analyses of large prospective trials. While all assays have shown their ability to provide prognostic information, the concordance between different assays is quite low $[3,4]$. Whether the mentioned assays have a predictive value, that is, if they offer information on the benefit derived from adjuvant chemotherapy due to a differential treatment effect in different risk strata is the subject of ongoing investigations. The debate on the use of gene expression assays has been fueled by the publication of results from 2 large randomized controlled trials, the MINDACT trial [5] and the TAILORx trial [6].

Adjuvant radiotherapy is a standard treatment for breast cancer patients after breast-conserving surgery (BCS) and after mastectomy (in the presence of risk factors). However, there are several clinical scenarios in which the role of adjuvant radiotherapy has been questioned (Table 2) due to small absolute benefits $[7,8]$ and possible short- and long-term side effects [9-12]. Nowadays, the indication for adjuvant radiation is based on patient and tumor characteristics, such as age, tumor and 
nodal stage, hormone receptor status, HER2 status, grading, and lymphovascular invasion $[8,13-15]$. Due to the rising percentage of patients that receive testing with one of the available gene expression assays, there is a growing interest in determining the role of these assays for the indication of adjuvant radiotherapy [16].

This review summarizes the commercially available assays and the relevant literature on the correlation between the test results and the risk of locoregional recurrence as well as other outcome parameters. Several groups have tried to establish gene expression assays specifically designed for determining the efficacy of radiotherapy in different settings [17-21]. Most of these results have been generated using cohorts from historic trials, such as DBCG 82b/c [21] and SweBCG91-RT [19]. However, it is currently not clear whether these data are applicable to patients receiving contemporary treatment. Furthermore, these gene expression assays are currently not available for clinical use. Thus, a detailed discussion of radiotherapy-specific gene expression assays is beyond the scope of this review. Furthermore, data on prediction of late toxicity using genome-wide association studies will not be discussed. There are no data concerning the use of gene expression assays for the prediction of locoregional recurrence in the neoadjuvant setting [22].

\section{Summary of Commercially Available Gene Expression Assays}

\section{Oncotype DX}

The Oncotype DX test was derived from a set of 21 prospectively selected genes based on 250 candidate genes tested in 3 independent pilot studies and was validated using clinical data from NSABP B-14 [23]. Different definitions of low-, intermediate-, and high-risk recurrence score groups have been used. While the original publication by Parker et al. [24] established cutoffs of $<18,18-30$, and $\geq 31$ [23], the TAILORx trial set these at $<11,11-25$, and $\geq 26$ [6]. In a retrospective analysis, the rate of distant recurrence at 10 years in 668 tamoxifen-treated patients from NSABP B-14 was 6.8, 14.3, and 30.5\% in the low-, intermediate-, and high-risk groups, respectively [23]. Furthermore, the prognostic role of the Oncotype DX score has been shown in patients with node-positive disease treated with endocrine or chemo-endocrine therapy $[25,26]$. Using data from the SWOG-8814 trial, Albain et al. [25] could show that there was no benefit of adding adjuvant chemotherapy to endocrine therapy in patients with low Oncotype DX scores, while patients with high Oncotype DX scores did significantly profit from additional chemotherapy. This suggests a predictive value of Oncotype DX scores for adjuvant chemotherapy.
The TAILORx trial is a prospective randomized controlled phase III trial assessing the role of the Oncotype DX assay. In total, 10,273 patients with early-stage, hormone receptor-positive, HER2-negative, node-negative breast cancer were enrolled. Patients with a recurrence score $\leq 10$ received endocrine therapy alone, while patients with a recurrence score $\geq 26$ were treated with endocrine therapy plus chemotherapy. Patients with a recurrence score of 11-25 were randomly assigned to receive endocrine therapy alone or chemotherapy followed by endocrine therapy. Results from the cohort of patients with a recurrence score $\leq 10$ were published in 2015 and showed a very favorable outcome of this subgroup with a 5-year distant metastasis-free survival (DMFS) of 98.7\% [27]. At the 2018 Annual Meeting of the American Society of Clinical Oncology, results from the randomly assigned intermediate-risk patients were presented and simultaneously published in the New England Journal of Medicine [6]. Among the 6,711 patients with a recurrence score of 11-25, endocrine therapy was noninferior to endocrine therapy plus chemotherapy with 5-year invasive disease-free survival rates of 92.8 and $93.1 \%$, respectively. However, patients aged 50 years or younger and with a recurrence score of 16-20 or 21-25 had a significantly lower risk of failure at a distant site when treated with chemotherapy and endocrine therapy as compared to patients who received endocrine therapy alone.

\section{Prosigna/PAM50}

The Prosigna test is based on the PAM50 assay published by Parker et al. [24]. The PAM50 was established using gene expression data from quantitative reverse transcriptase polymerase chain reaction and microarray from publicly available datasets for the prediction of molecular subtypes. The number of genes was sequentially reduced from 1,906 to 161 genes and finally to 50 genes. A risk of recurrence (ROR) score was obtained by using subtype correlation along with tumor size. The training set consisted of 141 untreated patients from a prospective cohort. Results were validated on a cohort of 279 patients with heterogeneous treatment and a cohort of 133 patients who received neoadjuvant treatment. The commercially available Prosigna assay uses 46 of the 50 original gene transcripts [28]. The PAM50 assay was validated on 1,478 patients from the ABCSG 8 [29] as well as on 543 node-positive patients from ABCSG 8 and ATAC [30], all of which were treated with endocrine therapy alone and all of which were postmenopausal.

In contrast to the other gene expression assays, PAM50 offers information on the intrinsic subtype and the ROR and is also applicable to hormone receptor-negative and/ or HER2-positive breast cancer, although the clinical utility has not been proven in this setting [31]. 
Table 3. Clinical trials studying the role of gene expression assays for adjuvant radiotherapy in breast cancer

\begin{tabular}{|c|c|c|c|c|}
\hline & $\begin{array}{l}\text { IDEA } \\
\text { (NCT02400190) }\end{array}$ & $\begin{array}{l}\text { PRECISION } \\
\text { (NCT02653755) }\end{array}$ & $\begin{array}{l}\text { EXPERT } \\
\text { (NCT02889874) }\end{array}$ & $\begin{array}{l}\text { TAILOR RT } \\
\text { (NCT03488693) }\end{array}$ \\
\hline Design & $\begin{array}{l}\text { Prospective observational } \\
\text { single-arm trial }\end{array}$ & $\begin{array}{l}\text { Prospective observational } \\
\text { 2-arm trial }\end{array}$ & $\begin{array}{l}\text { Randomized controlled } \\
\text { phase III noninferiority trial }\end{array}$ & $\begin{array}{l}\text { Randomized controlled } \\
\text { phase III trial }\end{array}$ \\
\hline $\begin{array}{l}\text { Gene expression } \\
\text { assay }\end{array}$ & $\begin{array}{l}\text { Oncotype DX } \\
\text { (recurrence score } \leq 18 \text { ) }\end{array}$ & PAM50/Prosigna & $\begin{array}{l}\text { PAM50/Prosigna } \\
\text { (luminal A subtype) }\end{array}$ & $\begin{array}{l}\text { Oncotype DX } \\
\text { (recurrence score <18) }\end{array}$ \\
\hline Setting & $\begin{array}{l}\text { BCS, low-risk } \\
\text { constellation }\end{array}$ & $\begin{array}{l}\text { BCS, low-risk } \\
\text { constellation }\end{array}$ & $\begin{array}{l}\text { BCS, low-risk } \\
\text { constellation }\end{array}$ & $\begin{array}{l}\text { BCS or mastectomy, } \\
\text { pT1-2 N1a }\end{array}$ \\
\hline $\begin{array}{l}\text { Treatment } \\
\text { arms }\end{array}$ & No RT & $\begin{array}{l}\text { - Low risk per ROR: no RT } \\
\text { - Intermediate/high risk } \\
\text { per ROR: WBI }\end{array}$ & $\begin{array}{l}\text { - WBI } \\
\text { - No RT }\end{array}$ & $\begin{array}{l}\text { BCS: } \\
\text { - WBI } \\
\text { - WBI + RNI } \\
\text { Mastectomy: } \\
\text { - No RT } \\
\text { - PMRT + RNI }\end{array}$ \\
\hline Patient number & 202 & 690 & 1,167 & 2,140 \\
\hline Primary endpoint & Locoregional recurrence & Locoregional recurrence & Local recurrence & $\begin{array}{l}\text { Breast cancer } \\
\text { recurrence-free interval }\end{array}$ \\
\hline
\end{tabular}

BCS, breast-conserving surgery; RT, radiotherapy; ROR, risk of recurrence; WBI, whole-breast irradiation; RNI, regional nodal irradiation; PMRT, post-mastectomy radiotherapy.

\section{EndoPredict}

The EndoPredict test is based on gene expression from 8 cancer-related and 4 reference genes using quantitative reverse transcriptase polymerase chain reaction. In contrast to PAM50 and Oncotype DX, ER, PR, and HER2 are not included [31]. Using information on tumor size and nodal status, the comprehensive EPclin score can be derived. The EPclin score was validated using patient data from ABCSG 6 and 8, two randomized controlled trials testing different endocrine therapy combinations [32].

\section{MammaPrint}

The MammaPrint assay is based on the gene expression of 70 genes. This gene expression signature was developed using fresh frozen tissue from 295 patients treated at the Netherlands Cancer Institute, comprising both patients with ER-positive and -negative tumors. The assay identified patients with either a good or a poor prognostic signature among various subgroups, including node-positive patients and patients deemed low risk per the St. Gallen criteria established in 2001 [33]. For all patients included in the analysis, 10-year overall survival was $94.5 \%$ for good-prognosis patients and $54.6 \%$ for poor-prognosis patients. Similar discrimination was achieved for DMFS.

The RASTER trial prospectively assessed the impact of MammaPrint testing on the management of patients with cT1-4 cN0 cM0 breast cancer [34]. While 427 patients were eligible for assessment, 158 patients had to be excluded due to sampling failure or incorrect procedure.
Compared to clinical risk assessment with Adjuvant! Online, Nottingham Prognostic Index, or St. Gallen guidelines, MammaPrint testing identified fewer patients at high risk with a recommendation for adjuvant chemotherapy. However, the Dutch CBO guidelines were more restrictive in terms of chemotherapy recommendation. Discordance between clinical risk assessment and MammaPrint results was between 27 and 39\%.

Knauer et al. [35] assessed the predictive value of the MammaPrint assay using a cohort of 541 patients treated at different institutions outside of a clinical trial with endocrine therapy alone or endocrine therapy plus chemotherapy. Patients with MammaPrint low-risk scores had a 5-year breast cancer-specific survival rate of $97 \%$ when treated with endocrine therapy alone versus $99 \%$ after endocrine therapy plus chemotherapy (HR 0.58, 95\% CI $0.07-4.98$ ) compared to 81 and $94 \%$ for patients with MammaPrint high-risk scores (HR 0.21, 95\% CI 0.07$0.59)$.

The MINDACT trial used the MammaPrint assay and enrolled 6,693 patients with early-stage breast cancer [5]. The ROR was assessed with the MammaPrint assay (genomic risk) and the Adjuvant! Online tool (clinical risk). Patients deemed to be at low risk using both methods received endocrine therapy alone, while patients with clinical and genomic high risk received additional chemotherapy. Patients with discordant results from the clinical and genomic risk stratification were randomized to receive endocrine therapy alone or endocrine therapy plus chemotherapy. The primary endpoint was to show that for 
patients with clinical high-risk and genomic low-risk constellation and who did not receive chemotherapy, the lower boundary of the $95 \%$ CI of the 5-year DMFS is higher than $92 \%$, employing a noninferiority design. $98.2 \%$ of patients had T1/2 tumors, $79 \%$ were node negative, and $80.7 \%$ had hormone receptor-positive HER2-negative tumors. The MammaPrint assay was performed on fresh frozen tissue obtained at surgery, which was not feasible for technical reasons in 1,182 patients ( $26 \%$ of screening failures). The 5-year DMFS in the above-mentioned subgroup was $94.7 \%$ (95\% CI 92.5-96.2); thus, the primary endpoint was met. There was no statistically significant difference in 5-year DMFS when comparing patients who were deemed to be at high risk based on clinical versus genomic assessment; however, the use of chemotherapy was reduced by $46.2 \%$ in the genomic-risk group.

\section{Correlation between Results from Commercially Available Gene Expression Assays and Locoregional Recurrence}

There are several clinical scenarios in which the identification of different prognostic subgroups regarding the risk of locoregional recurrence could be of special importance due to the relatively small absolute benefit and limited usefulness of standard clinicopathological parameters for therapeutic decision-making regarding adjuvant radiotherapy (Table 3 ).

\section{Oncotype DX}

The relationship between Oncotype DX scores and risk of locoregional recurrence has been studied extensively. The first results were derived from a subgroup of patients from the NSABP B-14 and B-20 trials [36]. Among 895 node-negative, tamoxifen-treated patients, the 10 -year risk of locoregional recurrence was 4.3, 7.2, and $15.8 \%$ for patients with low, intermediate, and high risk scores, respectively. Oncotype DX recurrence score was an independent predictor of locoregional recurrence when used as a dichotomous variable. There was a significant interaction between recurrence score categories and type of local treatment with little additional prognostic information in women $>50$ years compared to younger patients who both underwent BCS or in patients who underwent mastectomy. Of note, regional nodal irradiation and post-mastectomy radiotherapy (PMRT) were not allowed per protocol.

Recently, data for 1,065 ER- and node-positive patients from NSABP B-28 were published [37]. All patients received tamoxifen and chemotherapy with either doxorubicin/cyclophosphamide or the same regimen followed by paclitaxel. Radiotherapy recommendations were the same as for B-14/B-20. Sixty-eight percent of included pa- tients had 1-3 involved lymph nodes, while $<5 \%$ presented with 10 or more involved lymph nodes. Again, Oncotype DX recurrence score predicted locoregional recurrence upon multivariate analysis. While results were not statistically significant for patients with 1-3 involved lymph nodes, the 10-year risk of locoregional recurrence was $3.5,11.6$, and $20.3 \%$ for patients with $\geq 4$ involved lymph nodes and a recurrence score of $0-17,18-30$, and $>30$, respectively $(p=0.001)$. Results were similar when grouping patients according to the type of surgery and number of involved lymph nodes.

Prior results from a retrospective analysis of the ECOG E197 trial showed no statistically significant association of Oncotype DX recurrence scores and local or locoregional recurrence among 388 patients with 1-3 involved lymph nodes who were treated with chemo-endocrine therapy [38]. However, the analysis was considerably smaller than for the NSABP B-28 study and only included patients with BCS. Furthermore, the authors included ER-negative patients with available Oncotype DX results. When excluding these patients, there was a significant association between the recurrence score as a continuous variable and locoregional, but not local recurrence.

Turashvili et al. [39] performed a retrospective analysis of 2,326 ER-positive, node-negative patients who received treatment at Memorial Sloan Kettering Cancer Center from 2008 to 2013 and had an Oncotype DX test performed. This included mostly patients with BCS and radiotherapy and patients having a mastectomy without adjuvant radiotherapy. The cumulative 4 -year risk of locoregional recurrence was $0.8,2.7$, and $2.8 \%$ for patients with low, intermediate, and high recurrence scores, respectively $(p<0.01)$. Upon multivariate analysis, the hazard ratios for locoregional recurrence for intermediateand high-risk patients compared to low-risk patients were 2.8 (1.4-5.6) and 4.6 (1.9-11.2). Turashvili et al. [40] recently published further results on 1,396 node-negative patients with a recurrence score $<18$, showing that the locoregional recurrence rate was $0.9 \%$ at a median followup of 52 months.

Jegadeesh at al. [41] analyzed the outcome of 163 patients from their institution that had Oncotype DX results available and received treatment from 2006 to 2009. Fiftythree patients underwent mastectomy alone, while 110 patients had BCS followed by adjuvant radiotherapy. Among mastectomy patients, a recurrence score of $>24$ was associated with a significantly higher risk of locoregional recurrence. Interestingly, all patients had AJCC stage I or II and $81 \%$ had no involved lymph nodes.

Jayasekera et al. [42] took a different approach than the previously mentioned studies. They evaluated 7 prospective clinical trials that addressed the role of radiotherapy after BCS in low-risk patients. From these trials, they selected patients aged $40-75$ years with $\mathrm{T} 1$ breast cancer who were 
node negative and ER or PR positive and HER2 negative or unknown with an Oncotype DX score of 18 or lower. Apart from patients from the TAILORx trial, Oncotype DX scores were not available and were imputed using a populationbased donor dataset provided by Genomic Health, the manufacturer of Oncotype DX. 1,778 patients were included in the analysis, of which 1,405 received radiotherapy. Since random assignment was no longer applicable, multivariable Cox proportional hazards models were used for statistical analysis. Radiotherapy significantly improved 5and 10-year recurrence-free interval (RFI) rates with an absolute benefit of $4.4 \%$ after 5 years and $9.2 \%$ after 10 years. Improvement in locoregional RFI was similar; however, there was no significant difference in breast cancer-specific and overall survival. While the risk of bias is considerable due to the study design, there was no major difference in terms of radiotherapy-associated RFI benefit for patients with an Oncotype DX recurrence score of 1-10 (absolute benefit $3.9 \%$ ) compared to patients with a recurrence score of 11-18 (absolute benefit 5.3\%).

\section{Prosigna/PAM50}

The association between PAM50 and the risk of locoregional recurrence has been studied using material and clinical data from 1,308 patients enrolled in the ABCSG 8 trial, a randomized clinical trial testing tamoxifen versus tamoxifen followed by anastrozole in the adjuvant treatment of hormone receptor-positive breast cancer. Results were presented at the ASCO Annual Meeting in 2014. With a median follow-up of 11 years, the risk of locoregional recurrence was significantly higher for patients with a high ROR $(\geq 57)$ compared to patients with a low ROR $(<57)$ [43]. Furthermore, results from a nationwide study from Denmark have been presented [44]. PAM50 results were available for 2,722 postmenopausal breast cancer patients with a median follow-up of $>9$ years. Again, PAM50 high risk versus low risk was an independent risk factor for locoregional recurrence.

\section{EndoPredict}

Fitzal et al. [45] studied the association between EndoPredict scores and the risk of local recurrence among 1,324 patients enrolled in the ABCSG 8 trial. The risk of local recurrence was significantly higher for EndoPredict high-risk patients than for low-risk patients. With a median follow-up of 72.3 months, the local recurrence-free survival was $96.2 \%$ for high-risk patients compared to 98.6\% for low-risk patients.

\section{MammaPrint}

The relationship between MammaPrint test results and local recurrence was analyzed by Drukker et al. [46] using data of 1,053 patients from different validations treated at the Netherlands Cancer Institute from 1984 to 2006. Mam-
maPrint scores were strongly correlated with the risk of locoregional recurrence, which was 6.1 and $12.6 \%$ at 10 years for patients with low-risk and high-risk scores, respectively. The MammaPrint risk category was independently associated with the risk of locoregional recurrence on multivariate analysis with a hazard ratio of 1.73 (95\% CI 1.02-2.93). However, this association was time dependent with a significant effect in the first 5 years and no relation thereafter.

\section{Predictive Value of Gene Expression Assays for Radiotherapy Benefit}

Despite the data listed above suggesting additional prognostic information from gene expression assays, it remains unclear whether the results of gene expression assays might have a predictive value for radiotherapy. There are few studies so far that have analyzed the possible predictive role of gene expression assays for radiotherapy.

The study mentioned above by Fitzal et al. [45] studied the association between EndoPredict/EPclin results and local recurrence. A subgroup of 499 patients who had had BCS with or without adjuvant radiotherapy was further studied. Adjuvant radiotherapy significantly decreased the risk of local recurrence in both low- and high-risk patients without any evidence of a differential therapeutic effect according to the EndoPredict risk category [47].

A recent publication by Dong et al. [48] studied the role of adjuvant radiotherapy in low-risk patients undergoing BCS. Using the SEER database, they identified 13,246 breast cancer patients with T1-2 N0 tumors who were ER positive, younger than 65 years, received their diagnosis from 2004 to 2010, and had undergone Oncotype DX testing. Eighty percent of patients received adjuvant radiotherapy. Oncotype DX risk category was highly correlated with the probability of omission of adjuvant radiotherapy. Adjuvant radiotherapy was associated with a significant benefit in breast cancer-specific survival. However, when studying the effect of radiotherapy in the different Oncotype DX risk categories, only patients with intermediate risk scores (as per the TAILORx cutoffs or the traditional cutoffs) had a significant breast cancerspecific survival benefit, which was not the case for patients with low or high recurrence risk scores. This effect persisted after propensity score matching. There are several caveats to this study. Omission of adjuvant radiotherapy after BCS in patients at the age of 51-65 years is not supported by current national or international guidelines. No information on the HER2 status or details on the radiotherapy treatment was available. The SEER database does not contain information on patterns of recurrence.

Goodman et al. [49] performed a retrospective population-based analysis of the SEER registry and the NCDB. They included patients with ER-positive, $\mathrm{pT} 1-2 \mathrm{pN} 1$ breast 
cancer who had had a mastectomy and had undergone Oncotype DX testing between 2004 and 2014. Patients with neoadjuvant chemotherapy, no endocrine therapy, radiotherapy dose $<45 \mathrm{~Gy}$, or a follow-up time $<2$ months were excluded. A documented recurrence score was available for approximately $10 \%$ of patients for both databases, yielding 3,087 and 7,332 eligible patients from SEER and NCDB, respectively. In the SEER and the NCDB dataset, 19.6 and $27 \%$ of patients received PMRT, respectively. Multivariable parametric accelerated failure time models were used to account for significant nonproportional hazards between recurrence score groups and according to the use of PMRT. Propensity score-matched and inverse probability-weighted cohort analyses were applied to reduce potential confounding. Upon multivariable analysis, low-risk patients treated with PMRT had a significantly longer overall survival compared to low-risk patients who did not have radiotherapy in both cohorts. There was no association between PMRT and overall survival for patients with intermediateor high-risk recurrence scores.

In a similar approach, Zhang et al. [50] conducted a retrospective study on the effect of PMRT in patients with pT1-2 pN1mic, ER-positive, HER2-negative breast cancer who had Oncotype DX testing. 1,571 patients from the SEER database were included, of which $61.7 \%$ had a lowrisk recurrence score $(<18)$. No overall survival or breast cancer-specific survival benefit was seen in the overall cohort or in subgroups per the recurrence score results. However, in the 93 patients with a high-risk recurrence score, the group of patients treated without PMRT had a significantly better breast cancer-specific survival. The validity of the findings is limited. The role of adjuvant PMRT in patients with pT1-2 pN1mic is debatable, which is reflected by the low number of patients who received PMRT (16.2\%). There are no prospective or retrospective data suggesting a survival benefit from PMRT in these patients $[51,52]$.

\section{Conclusions}

There are multiple studies suggesting a correlation between results from gene expression assays and locoregional recurrence rates. Due to methodological weak- nesses and limitations regarding patient selection, the nonrandomized design of these studies in terms of radiotherapy use, as well as low rates of tissue availability, utilization of these results for clinical decision-making regarding radiotherapy should be very cautious. The available evidence on the predictive value of gene expression assays for radiotherapy does not support their inclusion into the decision-making process for adjuvant radiation as of now. Several ongoing prospective trials will hopefully shed further light on the usefulness of gene expression assays for adjuvant radiotherapy in breast cancer patients (Table 3).

\section{Acknowledgements}

The authors would like to thank Prof. Frederik Marmé, University Hospital Mannheim, for providing valuable insights from a gyneco-oncological perspective.

\section{Statement of Ethics}

The authors have no ethical conflicts to disclose.

\section{Disclosure Statement}

D.K. has received honoraria from Merck Sharp and Dome. R.B., W.B., M.N.D., J.D., P.F., R.F., W. Haase, W. Harms, T.H., M.D.P., F.S., R. Souchon, F.W., and R. Sauer declare that they have no conflicts of interest.

\section{Funding Sources}

There was no funding for this article.

\section{Author Contributions}

D.K. designed the analysis, acquired and analyzed the data, and wrote the first draft of the manuscript. R.B., W.B., M.N.D., J.D., P.F., R.F., W. Haase, W. Harms, T.H., M.D.P., F.S., R. Souchon, F.W., and R. Sauer analyzed the data, critically revised the manuscript, and provided important intellectual content. All authors approved the final version of the manuscript for publication.

\section{References}

1 Perou CM, Sørlie T, Eisen MB, van de Rijn M, Jeffrey SS, Rees CA, et al. Molecular portraits of human breast tumours. Nature. 2000 Aug; 406(6797):747-52.

2 Sørlie T, Perou CM, Tibshirani R, Aas T, Geisler S, Johnsen H, et al. Gene expression patterns of breast carcinomas distinguish tumor subclasses with clinical implications. Proc Natl Acad Sci USA. 2001 Sep;98(19): 10869-74.
3 Fan C, Oh DS, Wessels L, Weigelt B, Nuyten DS, Nobel AB, et al. Concordance among gene-expression-based predictors for breast cancer. N Engl J Med. 2006 Aug;355(6):5609.

4 Prat A, Parker JS, Fan C, Cheang MC, Miller LD, Bergh J, et al. Concordance among gene expression-based predictors for ER-positive breast cancer treated with adjuvant tamoxifen. Ann Oncol. 2012 Nov;23(11):2866-73.
5 Cardoso F, van't Veer LJ, Bogaerts J, Slaets L, Viale G, Delaloge S, et al.; MINDACT Investigators. 70-Gene Signature as an Aid to Treatment Decisions in Early-Stage Breast Cancer. N Engl J Med. 2016 Aug;375(8):717-29.

6 Sparano JA, Gray RJ, Makower DF, Pritchard KI, Albain KS, Hayes DF, et al. Adjuvant Chemotherapy Guided by a 21-Gene Expression Assay in Breast Cancer. N Engl J Med. 2018 Jul;379(2):111-21. 
7 Abdel-Rahman O. Impact of postmastectomy radiotherapy on the outcomes of breast cancer patients with T1-2 N1 disease : an individual patient data analysis of three clinical trials. Strahlenther Onkol. 2019 Apr;195(4): 297-305.

8 Wenz F, Budach W. Personalized radiotherapy for invasive breast cancer in 2017 : national S3 guidelines and DEGRO and AGO recommendations. Strahlenther Onkol. 2017 Aug;193(8):601-3.

9 Corradini S, Ballhausen $\mathrm{H}$, Weingandt $\mathrm{H}$, Freislederer P, Schönecker S, Niyazi M, et al. Left-sided breast cancer and risks of secondary lung cancer and ischemic heart disease effects of modern radiotherapy techniques. Strahlenther Onkol. 2018 Mar;194(3):196205.

10 Piroth MD, Baumann R, Budach W, Dunst J, Feyer P, Fietkau R, et al. Heart toxicity from breast cancer radiotherapy : current findings, assessment, and prevention. Strahlenther Onkol. 2018 Oct;88:1659-12.

11 Strouthos I, Chatzikonstantinou G, Tselis N, Bon D, Karagiannis E, Zoga E, et al. Photobiomodulation therapy for the management of radiation-induced dermatitis : A single-institution experience of adjuvant radiotherapy in breast cancer patients after breast conserving surgery. Strahlenther Onkol. 2017 Jun; 193(6):491-8.

12 Vasiljevic D, Arnold C, Neuman D, Fink K, Popovscaia M, Kvitsaridze I, et al. Occurrence of pneumonitis following radiotherapy of breast cancer - A prospective study. Strahlenther Onkol. 2018 Jun;194(6):520-32.

13 Krug D, Baumann R, Budach W, Dunst J, Feyer P, Fietkau R, et al.; Breast cancer expert panel of the German Society of Radiation Oncology (DEGRO). Current controversies in radiotherapy for breast cancer. Radiat Oncol. 2017 Jan;12(1):25.

14 Sautter-Bihl ML, Sedlmayer F, Budach W, Dunst J, Feyer P, Fietkau R, et al.; Breast Cancer Expert Panel of the German Society of Radiation Oncology (DEGRO). DEGRO practical guidelines: radiotherapy of breast cancer III-radiotherapy of the lymphatic pathways. Strahlenther Onkol. 2014 Apr;190(4):342-51.

15 Wenz F, Sperk E, Budach W, Dunst J, Feyer P, Fietkau R, et al.; Breast Cancer Expert Panel of the German Society of Radiation Oncology (DEGRO). DEGRO practical guidelines for radiotherapy of breast cancer IV: radiotherapy following mastectomy for invasive breast cancer. Strahlenther Onkol. 2014 Aug;190(8): 705-14.

16 Braunstein LZ, Taghian AG. Molecular Phenotype, Multigene Assays, and the Locoregional Management of Breast Cancer. Semin Radiat Oncol. 2016 Jan;26(1):9-16.

17 Kreike B, Halfwerk H, Kristel P, Glas A, Peterse $\mathrm{H}$, Bartelink $\mathrm{H}$, et al. Gene expression profiles of primary breast carcinomas from patients at high risk for local recurrence after breast-conserving therapy. Clin Cancer Res. 2006 Oct;12(19):5705-12.

18 Servant N, Bollet MA, Halfwerk H, Bleakley K, Kreike B, Jacob L, et al. Search for a gene expression signature of breast cancer local recurrence in young women. Clin Cancer Res. 2012 Mar;18(6):1704-15.
19 Sjöström M, Chang SL, Fishbane N, Davicioni E, Zhao SG, Hartman L, et al. Clinicogenomic Radiotherapy Classifier Predicting the Need for Intensified Locoregional Treatment After Breast-Conserving Surgery for EarlyStage Breast Cancer. J Clin Oncol. 2019 Dec; 37(35):3340-9.

20 Torres-Roca JF, Fulp WJ, Caudell JJ, Servant $\mathrm{N}$, Bollet MA, van de Vijver M, et al. Integration of a Radiosensitivity Molecular Signature Into the Assessment of Local Recurrence Risk in Breast Cancer. Int J Radiat Oncol Biol Phys. 2015 Nov;93(3):631-8.

21 Tramm T, Mohammed H, Myhre S, Kyndi M, Alsner J, Børresen-Dale AL, et al. Development and validation of a gene profile predicting benefit of postmastectomy radiotherapy in patients with high-risk breast cancer: a study of gene expression in the DBCG82bc cohort. Clin Cancer Res. 2014 Oct;20(20): 5272-80.

22 Krug D, Baumann R, Budach W, Dunst J, Feyer P, Fietkau R, et al.; Breast Cancer Expert Panel of the German Society of Radiation Oncology (DEGRO). Neoadjuvant chemotherapy for breast cancer-background for the indication of locoregional treatment. Strahlenther Onkol. 2018 Sep;194(9):797-805.

23 Paik S, Shak S, Tang G, Kim C, Baker J, Cro$\operatorname{nin} M$, et al. A multigene assay to predict recurrence of tamoxifen-treated, node-negative breast cancer. N Engl J Med. 2004 Dec; 351(27):2817-26.

24 Parker JS, Mullins M, Cheang MC, Leung S, Voduc D, Vickery T, et al. Supervised risk predictor of breast cancer based on intrinsic subtypes. J Clin Oncol. 2009 Mar;27(8):1160-7.

25 Albain KS, Barlow WE, Shak S, Hortobagyi GN, Livingston RB, Yeh IT, et al.; Breast Cancer Intergroup of North America. Prognostic and predictive value of the 21-gene recurrence score assay in postmenopausal women with node-positive, oestrogen-receptor-positive breast cancer on chemotherapy: a retrospective analysis of a randomised trial. Lancet Oncol. 2010 Jan;11(1):55-65.

26 Dowsett M, Cuzick J, Wale C, Forbes J, Mallon EA, Salter J, et al. Prediction of risk of distant recurrence using the 21-gene recurrence score in node-negative and node-positive postmenopausal patients with breast cancer treated with anastrozole or tamoxifen: a TransATAC study. J Clin Oncol. 2010 Apr; 28(11):1829-34

27 Sparano JA, Gray RJ, Makower DF, Pritchard KI, Albain KS, Hayes DF, et al. Prospective Validation of a 21-Gene Expression Assay in Breast Cancer. N Engl J Med. 2015 Nov; 373(21):2005-14.

28 Dowsett M, Sestak I, Lopez-Knowles E, Sidhu K, Dunbier AK, Cowens JW, et al. Comparison of PAM50 risk of recurrence score with oncotype DX and IHC4 for predicting risk of distant recurrence after endocrine therapy. J Clin Oncol. 2013 Aug;31(22):2783-90.

29 Gnant M, Filipits M, Greil R, Stoeger H, Rudas M, Bago-Horvath Z, et al.; Austrian Breast and Colorectal Cancer Study Group. Predicting distant recurrence in receptor-positive breast cancer patients with limited clinicopathological risk: using the PAM50 Risk of Recurrence score in 1478 postmenopausal pa- tients of the ABCSG-8 trial treated with adjuvant endocrine therapy alone. Ann Oncol. 2014 Feb;25(2):339-45

30 Gnant M, Sestak I, Filipits M, Dowsett M, Balic M, Lopez-Knowles E, et al. Identifying clinically relevant prognostic subgroups of postmenopausal women with node-positive hormone receptor-positive early-stage breast cancer treated with endocrine therapy: a combined analysis of ABCSG-8 and ATAC using the PAM50 risk of recurrence score and intrinsic subtype. Ann Oncol. 2015 Aug;26(8): 1685-91.

31 Sinn P, Aulmann S, Wirtz R, Schott S, Marmé F, Varga Z, et al. Multigene Assays for Classification, Prognosis, and Prediction in Breast Cancer: a Critical Review on the Background and Clinical Utility. Geburtshilfe Frauenheilkd. 2013 Sep;73(9):932-40.

32 Filipits M, Rudas M, Jakesz R, Dubsky P, Fitzal F, Singer CF, et al.; EP Investigators. A new molecular predictor of distant recurrence in ER-positive, HER2-negative breast cancer adds independent information to conventional clinical risk factors. Clin Cancer Res. 2011 Sep;17(18):6012-20.

33 van de Vijver MJ, He YD, van't Veer LJ, Dai H, Hart AA, Voskuil DW, et al. A gene-expression signature as a predictor of survival in breast cancer. N Engl J Med. 2002 Dec; 347(25):1999-2009.

34 Bueno-de-Mesquita JM, van Harten WH, Retel VP, van 't Veer LJ, van Dam FS, Karsenberg $\mathrm{K}$, et al. Use of 70-gene signature to predict prognosis of patients with node-negative breast cancer: a prospective communitybased feasibility study (RASTER). Lancet Oncol. 2007 Dec;8(12):1079-87.

35 Knauer M, Mook S, Rutgers EJ, Bender RA, Hauptmann M, van de Vijver MJ, et al. The predictive value of the 70-gene signature for adjuvant chemotherapy in early breast cancer. Breast Cancer Res Treat. 2010 Apr; 120(3):655-61.

36 Mamounas EP, Tang G, Fisher B, Paik S, Shak $\mathrm{S}$, Costantino JP, et al. Association between the 21-gene recurrence score assay and risk of locoregional recurrence in node-negative, estrogen receptor-positive breast cancer: results from NSABP B-14 and NSABP B-20. J Clin Oncol. 2010 Apr;28(10):1677-83.

37 Mamounas EP, Liu Q, Paik S, Baehner FL, Tang G, Jeong JH, et al. 21-Gene Recurrence Score and Locoregional Recurrence in NodePositive/ER-Positive Breast Cancer Treated With Chemo-Endocrine Therapy. J Natl Cancer Inst. 2017 Jan;109(4):djw259-8.

38 Solin LJ, Gray R, Goldstein LJ, Recht A, Baehner FL, Shak S, et al. Prognostic value of biologic subtype and the 21-gene recurrence score relative to local recurrence after breast conservation treatment with radiation for early stage breast carcinoma: results from the Eastern Cooperative Oncology Group E2197 study. Breast Cancer Res Treat. 2012 Jul; 134(2):683-92.

39 Turashvili G, Chou JF, Brogi E, Morrow M, Dickler M, Norton L, et al. 21-Gene recurrence score and locoregional recurrence in lymph node-negative, estrogen receptor-positive breast cancer. Breast Cancer Res Treat. 2017 Nov;166(1):69-76. 
40 Turashvili G, Brogi E, Morrow M, Dickler M, Norton L, Hudis C, et al. Breast carcinoma with 21-gene recurrence score lower than 18: rate of locoregional recurrence in a large series with clinical follow-up. BMC Cancer. 2018 Jan;18(1):42.

41 Jegadeesh NK, Kim S, Prabhu RS, Oprea GM, Yu DS, Godette KG, et al. The 21-gene recurrence score and locoregional recurrence in breast cancer patients. Ann Surg Oncol. 2015 Apr;22(4):1088-94.

42 Jayasekera J, Schechter CB, Sparano JA, Jagsi R, White J, Chapman JW, et al.; CISNETBOLD Collaborative Group. Effects of Radiotherapy in Early-Stage, Low-Recurrence Risk, Hormone-Sensitive Breast Cancer. J Natl Cancer Inst. 2018 Dec;110(12):1370-9.

43 Fitzal F, Filipits M, Fesl C, Rudas M, Dubsky $\mathrm{PC}$, Bartsch R, et al. Predicting local recurrence using PAM50 in postmenopausal endocrine responsive breast cancer patients. J Clin Oncol. 2014 May;32 15_suppl:1008.

44 Ole Eriksen J, Jensen MB, Laenkholm AV, Kibøll T, Bruun Rasmussen B, Knoop AS, et al. Abstract P2-08-10: Validation of prediction of local recurrence (LR) by Prosigna ${ }^{\circledR}$ (PAM50) in a Danish breast cancer cooperative group (DBCG) cohort of hormone recep- tor positive $(\mathrm{HR}+)$, postmenopausal early breast cancer (EBC) patients allocated to $5 \mathrm{yr}$ of endocrine therapy (ET). In: Proceedings of the Thirty-Eighth Annual CTRC-AACR San Antonio Breast Cancer Symposium: 2015 Dec 8-12; San Antonio, TX. Philadelphia (PA): AACR. Cancer Res. 2016 Feb; 76(4 Suppl):Abstract nr P2-08-10.

45 Fitzal F, Filipits M, Rudas M, Greil R, Dietze $\mathrm{O}$, Samonigg $\mathrm{H}$, et al. The genomic expression test EndoPredict is a prognostic tool for identifying risk of local recurrence in postmenopausal endocrine receptor-positive, her2neu-negative breast cancer patients randomised within the prospective ABCSG 8 trial. Br J Cancer. 2015 Apr;112(8):140510.

46 Drukker CA, Elias SG, Nijenhuis MV, Wesseling J, Bartelink H, Elkhuizen P, et al. Gene expression profiling to predict the risk of locoregional recurrence in breast cancer: a pooled analysis. Breast Cancer Res Treat. 2014 Dec;148(3):599-613.

47 Fastner G, Sedlmayer F, Widder J, Metz M, Geinitz H, Kapp K, et al. OC-0270 Antihormones with or without irradiation in breast cancer: 10-year results of the ABCSG 8A trial. Radiother Oncol. 2019;133:S132-3.
48 Dong Y, Zhang WW, Wang J, Sun JY, He ZY, Wu SG. The 21-gene recurrence score and effects of adjuvant radiotherapy after breast conserving surgery in early-stage breast cancer. Future Oncol. 2019 May;15(14):1629-39.

49 Goodman CR, Seagle BL, Kocherginsky M, Donnelly ED, Shahabi S, Strauss JB. 21-Gene Recurrence Score Assay Predicts Benefit of Post-Mastectomy Radiotherapy in T1-2 N1 Breast Cancer. Clin Cancer Res. 2018 Aug; 24(16):3878-3887.

50 Zhang WW, Tong Q, Sun JY, Hua X, Long ZQ, Deng JP, et al. 21-Gene Recurrence Score Assay Could Not Predict Benefit of Post-mastectomy Radiotherapy in T1-2 N1mic ERPositive HER2-Negative Breast Cancer. Front Oncol. 2019 Apr;9:270.

51 Mamtani A, Patil S, Stempel M, Morrow M. Axillary Micrometastases and Isolated Tumor Cells Are Not an Indication for Postmastectomy Radiotherapy in Stage 1 and 2 Breast Cancer. Ann Surg Oncol. 2017 Aug; 24(8):2182-2188.

52 Wu SP, Tam M, Shaikh F, Lee A, Chun J, Schnabel F, et al. Post-mastectomy Radiation Therapy in Breast Cancer Patients with Nodal Micrometastases. Ann Surg Oncol. 2018 Sep;25(9):2620-31. 